\title{
Atravessamentos metodológicos na pesquisa em Comunicação
}

\author{
Methodological intersections in Communication research \\ Cruces metodológicos en la investigación en Comunicación
}

DOI: https://doi.org/10.1590/1809-5844202121

\author{
Laura Wottrich ${ }^{1}$ \\ https://orcid.org/0000-0003-3876-0198
}

${ }^{1}$ (Universidade Federal do Rio Grande do Sul, Faculdade de Biblioteconomia e Comunicação, Programa de Pós-Graduação em Comunicação. Porto Alegre - RS, Brasil).

\section{Resumo}

O texto ${ }^{1}$ assume a centralidade da metodologia para a configuração do conhecimento comunicacional, a partir das suas processualidades investigativas. Ou seja, toma a metodologia não como um a priori, mas como um processo em que o pesquisador, ao configurar uma investigação, é também configurado por ela. O enfoque é discutir os processos de aprender e ensinar metodologia na Comunicação, formado por três atravessamentos: epistemológicos, políticos e subjetivos. A exploração dessas dimensões indica que o amadurecimento metodológico do campo comunicacional passa pelo debate da dependência epistêmica, das vinculações entre teoria e metodologia e da reflexividade, além do estímulo à curiosidade epistemológica e à configuração de lugares de escuta.

Palavras-chave: Metodologias. Comunicação. Ensino. Pesquisa. Reflexividade.

\begin{abstract}
This paper places methodology at the center of the configuration of communication knowledge in terms of its investigative processualities. That is, methodology is not seen as a given but, rather, as a process in which the researcher, in configuring research, is likewise configured by it themselves. The focus is to discuss the processes of learning and teaching methods in Communications from the perspective of three intersections: epistemological, political, and subjective. Exploring these dimensions reveals that the methodological maturation of the field of Communications includes discussions on epistemic dependence, on the links between theory and methodology, on reflexivity, as well as on the encouragement towards epistemological curiosity and the configuration of places of listening.
\end{abstract}

Keywords: Methodologies. Communications. Teaching. Research. Reflexivity.

1 Trabalho derivado do projeto de pesquisa "A análise metodológica no aprendizado e consolidação da prática de pesquisa no campo da Comunicação”, com apoio do Conselho Nacional de Desenvolvimento Científico e Tecnológico (MCTIC/CNPq N 28/2018). 


\section{Resumen}

El texto asume la centralidad de la metodología para la configuración del conocimiento comunicacional, en función de sus procesos de investigación. Es decir, toma la metodología no a priori, sino como un proceso en el que el investigador, al configurar una investigación, también está configurado por él. El objetivo es discutir los procesos de aprendizaje y de enseñanza de la metodología en la comunicación, formada por tres cruces: epistemológicos, políticos y subjetivos. La exploración de estas dimensiones revela que la maduración metodológica del campo comunicacional implica el debate sobre la dependencia epistémica, los vínculos entre la teoría y la metodología y la reflexividad, además del estimulo a la curiosidad epistemológica y la configuración de los lugares de escucha.

Palabras clave: Metodologías. Comunicación. Enseñanza. Investigación. Reflexividad.

\section{Introdução}

A metodologia é uma das instâncias fundadoras da práxis científica, embora essa afirmação nem sempre se reverta em atribuir a essa dimensão um lugar privilegiado na produção e reflexão sobre o conhecimento comunicacional. No relato de pesquisadores em formação, muitas vezes a metodologia é verbalizada como algo que atravessa o percurso de pesquisa: não exatamente como aquilo que irrompe da articulação processual em torno do objeto, provoca problematizações e suscita descobertas, mas, sim, como um entrave: "Eu queria muito pesquisar esse tema, mas aí tem a metodologia...”.

Os dilemas impostos por esses atravessamentos são o enfoque deste texto, com especial atenção nas relações de aprender e de ensinar metodologia na área da Comunicação. Um diálogo que estabeleço com as contribuições de Braga (2016), Barichello (2016), Martino (2016), Martino e Grohmann (2017), Martino e Marques (2018, 2019), Bonin (2011, 2012), Moura e Lopes (2016), Seibt et al. (2013), Barth (2018) e também a partir das trocas junto aos pares e discentes.

Nessas discussões, os relatos daqueles que contam um pouco mais as minúcias do chão de fábrica da disciplina de Metodologia da Pesquisa não são os mais animadores. Tangibilizando as conversas de corredor, Martino e Grohmann (2017) detectam um certo desprestígio em torno dessa disciplina, percepção aproximada ao que comentam outros docentes-pesquisadores sobre esse contexto. A situação não parece diferir nos eventos e fóruns acadêmicos, em que a discussão metodológica é ainda escassa (BARTH, 2018). Por outro ponto de vista, Seibt et al. (2013) evidenciam as dificuldades dos discentes em dar relevância à instância metodológica, em especial, no desenvolvimento de seus Trabalhos de Conclusão de Curso na área, algo que também aparece em Lacerda et al. (2013). A hesitação frente aos desafios postos à prática investigativa e metodológica do TCC não é exclusividade da Comunicação e também emerge em outras áreas, como Medicina (GUEDES; GUEDES, 2012), Ciências Contábeis (SANTOS et al., 2017) ou Geografia (PEREHOUSKEI; ANGELIS, 2011). 
Para abordar esse cenário, discuto como a instância metodológica se inscreve na pesquisa em Comunicação, para depois pensar nos atravessamentos que acontecem em sala de aula, que são inúmeros, e vou pontuar três: epistemológicos, políticos e subjetivos. Por fim, cabe discutir sobre como tornar, então, o aprendizado da metodologia uma instância produtiva e produtora aos sujeitos que estão em relação na construção de uma pesquisa.

\section{O lugar da metodologia}

Tomando a metodologia como o espaço primordial de refletir sobre o fazer pesquisa, é natural assumir sua importância e transversalidade à prática investigativa. A partir do modelo metodológico de Lopes (1990), a instância metodológica é um elemento constitutivo da prática de uma pesquisa, mesmo quando escamoteado ou pouco abordado. Ou seja, a estruturação de qualquer investigação é realizada a partir de um processo de tomada de decisões, no qual a problemática é montada, as teorias e a observação da realidade interagem - e se tensionam - continuadamente. Cabe à metodologia refletir em relação aos critérios de validade interna e de coerência entre esses elementos, que estão inscritos em um campo científico e ajudam a configurar e a responder a problemática de cada investigação. É um processo encarnado nas práticas concretas de uma pesquisa, como sintetiza Bonin (2011) 2 .

Tomada aqui como processualidade na construção de conhecimento, em um sentido amplo, é natural intuir que o bom manejo da metodologia é uma parte fundamental para a condição de produção do conhecimento de qualquer sujeito em nosso campo (LOPES, 1990). Ao fazer o metodológico, o sujeito também se refaz, em um movimento constitutivo da própria práxis científica (MALDONADO, 2003, BONIN, 2013). Dialoga com o que pontua Freire (2018, p. 25), quando diz que "Eu me movo como educador porque, primeiro, me movo como gente”. Nos movemos como pesquisadores porque, primeiro, assumimos nossa inscrição no mundo, e essa tomada de posição é em si um processo metodológico.

Se estabelecemos certo consenso sobre a centralidade da metodologia como pensar sobre um fazer no âmbito da produção de conhecimento na nossa área, cabe então à disciplina de Metodologias da Pesquisa (e suas variantes) constituir e estimular esse debate no âmbito do campo da Comunicação, tanto na graduação quanto na pós. Constitui-se, então, um espaço coletivo, formativo por excelência de futuros pesquisadores.

Como pontua Martino (2016, p. 28), junto à disciplina de Teorias da Comunicação, a de Metodologia da Pesquisa compõe “[...] o núcleo das discussões epistemológicas dentro de um curso de Comunicação [...] e tem a potência de ser um espaço de diálogo entre teorias e a investigação concreta”. Potência que algumas vezes pode se reduzir a um potencial não realizado. Alguns indícios de que isso acontece são a não rara detecção das ausências, em

2 Ou seja, não se trata de uma reflexão propriamente abstrata, mas vinculada ao cenário em que a investigação se realiza, como uma "dimensão que norteia, orienta, encaminha os processos de construção da pesquisa em todos os seus níveis, como instância corporificada em fazeres, operações, experimentações e procedimentos que dão feição ao objeto do conhecimento, que se inscrevem em lógicas atuantes na captura e fabricação pensada deste objeto” (BONIN, 2011, p. 2). 
teses e dissertações, do percurso que fundamentou a tomada de decisões na pesquisa. Isso foi identificado por Lopes (1990) ao analisar a constituição do campo no fim do século XX e também foi percebido em outras incursões mais específicas, como o projeto Meios \& Audiências, que acompanhou a produção acadêmica da área da recepção do mesmo período até 2015 (JACKS; MENEZES; PIEDRAS, 2007, JACKS, 2014, JACKS et al., 2017). Outro indício é o pouco número de títulos sobre metodologias da pesquisa no âmbito específico da Comunicação, em comparação às discussões teóricas. Como apontado por Martino e Marques (2018), se existem pelo menos 35 livros sobre teoria/epistemologia da pesquisa em comunicação, há apenas sete livros e alguns artigos sobre a instância e o fazer metodológico. E essas obras não figuram entre as referências mais mobilizadas nas ementas da graduação e pós-graduação, como evidenciam Moura (2016) e Martino e Grohmann (2017)3.

Outro ponto a ser ressaltado é a diversidade de nomes atribuídos à disciplina nos cursos de graduação, algo também evidenciado em uma pesquisa exploratória por Martino e Grohmann (2017): foram 20 nomes diferentes encontrados. Longe de esgotar essa questão, a pluralidade nas formas de nomear essa matéria pode ser indicativa de certa falta de consenso no campo sobre esse lugar do metodológico, como bem pontuam os autores.

Junto a isso - ou, justamente - devido a esse estado das coisas - não raras vezes a metodologia assume um caráter eminentemente prescritivo nas investigações, como uma bula que, em suas letras miúdas, apresenta regras em relação às margens de uma página e o espaçamento entre parágrafos. A instância metodológica é reduzida a um conjunto de prescrições formais que validam um trabalho como sendo "científico" e é também alijada do sujeito pesquisador que, na verdade, se constitui como o responsável pela definição da sua marcha. Aqui, o mesmo distanciamento entre sujeito e objeto que demarca certa visão positivista sobre a prática científica fala de um distanciamento entre o sujeito e a sua prática metodológica. Esse estado das coisas produz efeitos concretos na percepção e na vivência da metodologia nos processos de formação de pesquisadores, e aqui exploro especialmente três: os epistemológicos, os políticos e os subjetivos.

\section{Atravessamentos epistemológicos}

Os atravessamentos epistemológicos não são um assunto novo, remontam à constituição própria da Comunicação como um campo, suas fronteiras disciplinares, seu estatuto e sua identidade, tão debatidos no âmbito acadêmico. Na graduação, adquire peso o binarismo entre teoria e prática, sendo que a pesquisa é tomada por vezes como um ato apartado de teorização que pouco agregará na formação profissional dos sujeitos, dualidade que marca o estudo da comunicação desde seus anos inaugurais (LOPES, 1990). Isso emula

3 No estudo das referências teóricas mobilizadas em disciplinas de metodologias da pesquisa nos Programas de Pós-Graduação em Comunicação, Moura (2016) evidenciou a obra "Pesquisa qualitativa com texto, imagem e som” (Bauer, Gaskell) como a mais citada. A partir de um outro recorte, dessa vez direcionado a 33 cursos de jornalismo, Martino e Grohmann (2017) encontraram como obra mais citada o clássico "Metodologia do trabalho científico", de Lakatos e Marconi. Duas obras que dão insumos importantes para refletir sobre a instância metodológica, mas cuja relação com a comunicação não é uma preocupação. 
em pesquisas cuja instância teórica pouco ou nenhum diálogo estabelece com as escolhas metodológicas, em um sentido operativo do termo (MARTINO, 2016, MALDONADO, 2001, LOPES, 1990), configurando uma relação frágil entre essas dimensões. Aqui, pensar metodologicamente acaba se resumindo a "aplicar" a teoria. E pensar em se apropriar de uma teoria acaba se resumindo a "usar" um autor.

Um cenário que se torna mais complexo dada a condição do conhecimento comunicacional, heterogêneo, múltiplo, escorregadio. Como provoca Martino (2016), se não temos consenso sobre o que somos, quais são nossas visadas e nosso leque de preocupações, como poderemos desenvolver metodologias específicas? Dizendo em outros termos, de que modo, no processo de constituir teorias na Comunicação, operacionalizamos estratégicas metodológicas?

É um dilema que atravessa não apenas o campo da Comunicação, mas das ciências sociais como um todo, como alertou Lopes (1990). Ao passo em que está vinculada a perspectiva metodológica ampla e generalista, tributária de uma sintaxe e semântica próprias da linguagem científica, a Comunicação como ciência também é impelida a elaborar suas próprias metodologias de acordo com a natureza de suas preocupações (suas vinculações teóricas e seus objetos).

A partir disso, é necessário refletir, considerado o desenvolvimento do campo da Comunicação até aqui, se não é possível conectar de uma forma mais explícita a metodologia na pesquisa (em sua dimensão operativa) e a metodologia da pesquisa (em sua vinculação epistemológica) a partir das inquietações comunicacionais. Isso não significaria adotar uma visão estreita sobre a comunicação ${ }^{4}$, mas entender a metodologia como um sistema vivo que precisa ser constituído em tensionamento com o "estado das coisas”, com os constructos teóricos mobilizados no campo.

Assim, a valorização da instância metodológica não significa estabelecer o feixe de teorias comunicacionais às quais, necessariamente, a metodologia precisa obedecer, mas reivindicar uma articulação íntima entre a processualidade teórica e a metodológica na prática concreta das pesquisas. Isso, aos poucos, consolida um legado de intervenções, propostas e perspectivas metodológicas que podem ser questionadas e aprimoradas pelos pares.

Para evitar que esse movimento descambe para um novo fechamento, prescritivo e técnico, cabe sustentar a metodologia como esse lugar de articulação da práxis cientítica, lugar onde se realiza o processo de objetivação/subjetivação que orienta o sujeito na discussão científica sobre uma realidade concreta, num processo bachelardiano de vigilância epistemológica (LOPES, 1990, SODRÉ, 2003). Cultivar essa postura reflexiva e desconfiada frente ao formalismo e rigidez da metodologia ajuda também a desentranhar uma tradição mais positivista de ciência, na qual o método funcionaria como essa espécie de âncora para a manutenção de uma necessária posição objetiva e distanciada do pesquisador em relação

4 Afinal, como convoca a pensar Ferrara (2019, p.73), "Não cabe à epistemologia oferecer respostas corretas e confiáveis para a pesquisa em comunicação, mas oferecer-lhe argumentos que sustentem a eficiência empírica das dúvidas que pode sugerir”. Em suas vinculações com a processualidade metodológica da pesquisa, a epistemologia parece também cumprir esse papel. 
ao seu objeto (SODRÉ, 2003). Quando compreendemos a instância metodológica como uma práxis científica, abrimos espaço para o debate sobre os processos de objetivação, em que o objeto não é tomado em sua exterioridade, mas como um sistema de relações expressamente construído pelo pesquisador em todo o caminho da investigação (LOPES, 2010), ou seja, um espaço, por excelência, de reflexividade epistêmica.

Longe de querer resolver uma questão historicamente tão debatida como a identidade ou o objeto da Comunicação, penso que essas instabilidades epistemológicas atravessam o que conhecemos e principalmente o que sentimos em relação à metodologia. Retiram dessa disciplina, muitas vezes, a potência de ser o lugar por excelência da descoberta de um sujeito pesquisador que, em contato com o mundo, se vê capaz de formular perguntas, de questionar o que percebe a sua volta, de refinar o senso comum na constituição de uma problemática que ajude a entender melhor o que deseja investigar. Essa questão certamente não é específica do nosso campo. Ao contrário, ela diz respeito aos paradigmas científicos e seus embates, os quais vão desembocar de uma forma mais ou menos concreta nos aspectos subjetivos da pesquisa, conforme veremos adiante.

\section{Atravessamentos políticos}

Antes disso, cabe pensar nos atravessamentos políticos do aprendizado e ensino de metodologia, os quais, na verdade, não podem ser descolados dos demais. A partir da noção de campo, sabemos que o âmbito epistemológico sempre carrega uma dimensão política (LOPES, 2003). No entanto, aqui destaco esse "lugar" do político como os modos a partir do qual a produção do conhecimento é considerada, regulada e avaliada internamente e externamente ao campo.

Num lugar “além” dos muros das disputas internas do campo, há fatores históricos que se relacionam a essa falta de tenacidade metodológica, como a Comunicação se constituir apenas recentemente como um espaço específico de reflexões, ser um lugar “povoado de práticas instrumentais de saber-fazer técnico” (MALDONADO, 2003, p. 208), e ser geopoliticamente marcada em sua origem, nascida numa intensa relação com o poder político hegemônico (MALDONADO, 2003, SODRÉ, 2003). A dependência epistêmica é também relacionada a uma dependência metodológica, com a adoção acrítica de técnicas de pesquisa valorizadas pela ciência hegemônica (MALDONADO, 2012), o que se traduz em obstáculos e em inspiração para a pesquisa (MALDONADO, 2003) 5 .

Isso se relaciona também com as condições objetivas de produção e de circulação do conhecimento científico (NAVARRO, 2019), que não raras vezes se opõem à duração de um processo de investigação, não no sentido do tempo gasto, parametrizado, mas da duração em

5 "A efervescência sociocultural e política é um fator contextual que intervém significativamente na estruturação das condições de produção científica; tanto na geração de obstáculos sistêmicos quanto na inspiração e energia para problematizar as concepções comunicológicas e o mundo" (MALDONADO, 2003, p. 209). 
um sentido qualitativo do tempo, como fluxo, vivência, mobilidade, no sentido bergsoniano explorado por Rosário e Aguiar (2013).

Cabepensarquanto tempotem o tempoque temos, edequemodoa duração dos processos de pesquisa se articulam, confrontam e tensionam com os tempos institucionalizados. É nesse processo de objetivação dos tempos que muitas vezes se petrificam noções prescritivas de metodologia, como um checklist de ações que necessariamente precisa ser cumprido em determinado prazo. Sem esquecer, claro, das normas da ABNT... ${ }^{6}$

Por um outro lado, a consciência dessa noção política “intra” campo, em sala de aula, amplia a compreensão dos discentes sobre a práxis científica. Ao entender a ciência como um campo de disputas, os alunos aprofundam o conhecimento em torno das objetivações realizadas pelo campo comunicacional sobre os seus próprios temas de pesquisa. Isso os leva a problematizar por que certos objetos gozam de prestígio imediato, enquanto outros possuem pouco ou nenhum reconhecimento. Assim, uma afirmação realizada pelos alunos da análise mais imediata do estado das coisas no campo - "Se não há muitas pesquisas sobre o meu tema, é porque não é relevante” pode se tornar um processo de indagação construtiva sobre a constituição própria desse campo em que se questionem: "Mas por que mesmo que meu tema não é tão pesquisado?”.

\section{Atravessamentos subjetivos}

Por fim, cabe explorar um pouco mais os aspectos subjetivos do aprender e ensinar metodologia, os quais não estão apartados dos anteriores, mas são constituídos e constituintes dos mesmos (MARTINO; MARQUES, 2018). É esse o espaço de inscrição do sujeito pesquisador iniciante no mundo - acadêmico e fora dele. Esses elementos são pouco explorados em nossa tradição disciplinar, em comparação, por exemplo, a campos como a Antropologia, em que a reflexividade é uma dimensão fundante da práxis metodológica.

A opacidade da subjetividade é resultado de uma visão formalista da metodologia, ou, em uma perspectiva crítica, de sua dimensão colonial (BORSANI, 2014), sustentada em algumas falácias. A primeira é a impessoalidade dos relatos de pesquisa, nos quais subjaz algumas vezes uma pretensa neutralidade frente ao objeto investigado. Outra falácia é a noção da objetividade, não como inscrição reflexiva do pesquisador no processo de pesquisa, mas como uma externalidade que, quando não obedecida, corre o risco de “contaminar” a investigação.

\footnotetext{
6 Cabe, sob pena de incorrer em injustiças, ressaltar a importância do estabelecimento de normas para a constituição desse "terreno comum" em que a produção científica deve se situar. A metodologia não prescinde dessa dimensão, mas certamente não se resume a ela.

7 "Lo problemático estriba en su condición de colonizada, lo que es lo mismo decir que es el resultado de una imposición colonial en conformidad con los patrones de conocimiento euro-centrados. Dicha imposición responde a una estandarización del saber con pretensión de universalidad y neutralidad, según un reducido universo de problemas que es el que las ciencias sociales y las humanidades modeladas según lo que los patrones occidentales, reconocen como tales. Por ello, nuestra inquietud, disgusto o desasosiego no se sostiene sino en la dimensión colonial de la metodología, en advertir que es un área más de las tantas en las que ha hecho lo suyo la colonialidad del saber y sigue haciéndolo" (BORSANI, 2004, p. 152).
} 
Se não existe conhecimento a priori desinteressado, o maior risco se torna não explicitar os interesses da pesquisa (OROZCO GÓMEZ, 2000). Nesse processo, se torna necessária a objetivação da subjetividade, assumindo a vivência - derivada de uma localização social específica - uma das condições para a empreitada científica (MARTINO; MARQUES, 2017).

A indagação que podemos fazer aqui é: a partir do momento em que assumimos a subjetividade como ponto de partida de uma pesquisa, como, no processo de ensino da metodologia, podemos estimulá-la? Ao mesmo tempo, como evitar transformar a subjetividade numa condição suficiente para a validação de uma pesquisa, o que, no limite, significaria a interdição do conhecimento científico?

No âmbito dos cursos de graduação, em que a disciplina de Metodologias da Pesquisa não raras vezes se torna o primeiro contato do discente com o universo da prática científica, o processo de problematização inicial em torno do objeto pode ser um espaço privilegiado para uma tomada de consciência em torno da própria subjetividade, em um processo de objetivação que vai também constituindo a própria práxis científica (BRAGA, 2005). Há, aqui, elementos próprios dos processos de ensino-aprendizagem que são aliados na construção da aventura de pesquisa, de entender a dialogicidade da relação em sala de aula, em que todos ali presentes (discentes e docentes) se assumam como epistemologicamente curiosos, conforme ensina Freire (2018).

Cabe ao docente, no exercício de sua curiosidade como ser humano, pesquisador e educador, auxiliar os discentes no ofício intelectual de transformar suas curiosidades espontâneas sobre o mundo em curiosidades epistemológicas, a partir do estímulo às perguntas e a perguntar sobre as próprias perguntas que estão sendo elaboradas. Nesse contexto, pouco adianta ao docente questionar os alunos uma postura indagadora e curiosa sobre o tema que ele deseja investigar se não assume ele mesmo, na prática educativa, uma atitude também indagadora em relação ao conhecimento que está compartilhando com eles.

A vivência compartilhada em sala de aula da curiosidade epistemológica se torna um elemento importante no aprendizado de uma práxis científica, e é objetivado a partir de exercícios e estratégias pedagógicas específicos, mas também convoca o reconhecimento e estímulo à imaginação, à intuição e à emoção. A dimensão da intuição, pré-reflexiva, é um processo em que o sujeito entra no objeto, o vê em sua interioridade, não em sua exterioridade constitutiva (ROSÁRIO; AGUIAR, 2013). Na prática de pesquisa, a intuição constrói um domínio sensitivo-estético sobre o tema (MALDONADO, 2001), pois "Sem inteligência emotiva e estética, é impossível ter um pesquisador de talento; no máximo teremos um trabalhador esforçado das ideias e dos procedimentos” (MALDONADO, 2001, p. 61). Um processo que metodologicamente pode ser aproximado de um olhar atento às multiplicidades (ROSÁRIO; AGUIAR, 2013) ou de um gesto antropofágico (MACHADO, 2018). Gesto que podemos também associar à imagem do artesão intelectual apresentada por Mills (2009), quando rejeita o fetichismo do método e da técnica e inscreve a marca pessoal na costura de conceitos e procedimentos. 
O exercício da intuição na prática científica é um processo tentativo, do qual a própria experiência concreta de pesquisa torna-se balizadora. Para tomar emprestada a ideia de Martino e Marques (2018) sobre a "clínica de orientação”, cabe pensarmos no lugar de escuta que pode ser oportunizado em sala de aula, como "a disponibilidade permanente por parte do sujeito que escuta para a abertura e a fala do outro” (FREIRE, 2018, p. 117), o que não leva a “autoanulação” ou a impossibilidade de discordância, mas uma posição aberta e respeitosa às diferenças na qual, ao escutar, eu aprendo com.

No processo de aprendizagem da metodologia, o espaço de escuta vai aos poucos sendo delimitado pela mistura de timbres, visões e posições de mundo, e se potencializa ao ser vivenciado de forma coletiva. Um espaço no qual não somente o professor, mas a turma exerce a responsabilidade da escuta em relação aos projetos dos seus pares, como relatado, por exemplo, por Braga (2016). Cabe pensar um pouco sobre isso, sobre a responsabilidade da escuta. Como coloca Martino (2016), a ideia de responsabilidade já se vincula, de alguma forma, à possibilidade de uma resposta. Nesses processos de diálogo, surge um ambiente propício para a partilha de receios, dúvidas e intuições que geram faíscas criativas na constituição dos projetos de investigação.

Assim, o estímulo à curiosidade epistemológica, a criação de espaços para o exercício da intuição como elemento-chave da pesquisa e o incentivo à configuração de lugares coletivos de escuta parecem ser caminhos possíveis para trabalhar com a dimensão subjetiva na formação metodológica.

Nesse contexto, a inscrição social e individual específica do pesquisador se ressalta, mas também precisa ser localizada - objetivada - dentro do campo da Comunicação. Ou seja, precisa também ser inscrita no curso da história da produção desse conhecimento. É nesse momento que os anseios, indagações e intuições se tocam com a historicidade e as demandas próprias dos objetos de conhecimento do campo, que são também epistemológicas e políticas.

Nesse processo dinâmico, a realização da pesquisa da pesquisa (estado da arte) é uma porta interessante para a objetivação e inscrição dos interesses, como um movimento epistemológico, mas também político (MALDONADO, 2003) de olhar para os cânones, paradigmas do campo, entender sua construção interna, desconstruí-los e tensioná-los de acordo com os próprios interesses de investigação.

Em suma, a realização da pesquisa da pesquisa significa se inscrever como sujeito localizado no campo comunicacional, estabelecer diálogo com os pares, situando-se historicamente no processo de construção do conhecimento (BONIN, 2011). Estratégias como essa respondem à necessidade de racionalidade da prática de pesquisa (MARTINO; MARQUES, 2018), sem o qual, como pontuam os autores, corremos o risco de empreender uma investigação sustentada apenas em premissas afetivas ou em trilhar os caminhos que nos direcionem a ver apenas o que desejamos encontrar, fechando os olhos para as outras direções possíveis. 


\section{Por fim}

A centralidade da instância metodológica para a inscrição dos sujeitos pesquisadores no mundo parece se contrastar, pelos motivos aventados neste texto, ao tímido relevo dessa dimensão nas práticas e reflexões de pesquisa. O problema não é episódico, mas histórico, e informa as debilidades e potencialidades do campo comunicacional na construção do conhecimento científico.

No âmbito da graduação, em que muitas vezes a disciplina de Metodologias da Pesquisa é o único espaço de ensino dedicado à prática de investigação, a situação é mais sensível. O lugar por excelência de apresentação da lógica de produção do conhecimento, de formação de novos pesquisadores e de fomento a uma postura de indagação construtiva frente às inúmeras problemáticas do campo da Comunicação e do mundo, pode virar um lugar de reiteração da metodologia como instância meramente técnica e burocrática da vida acadêmica. Ou, ainda, lugar de cultivo de certo "cinismo epistêmico" (BORSANI, 2004), onde as próprias convicções são sacrificadas para obedecer a formalidades impostas por uma visão burocrática da metodologia, conformando-se a vivê-la como uma exigência protocolar, não como uma possibilidade de partilha sobre como fazemos e pensamos o nosso processo de pesquisa.

Logo no primeiro dia de aula, costumo dizer aos discentes que não nutro ilusões, embora gostaria de fazê-lo. Sei que não decidiram ingressar na Universidade porque viram que, lá pelo sexto semestre, teriam a disciplina de Metodologias da Pesquisa em Comunicação. A confissão é acolhida entre risos confortados de quem, não raras vezes, parece se identificar com essa imagem pré-figurada.

Os estudantes que não têm pretensões pela vida acadêmica após a faculdade, não poucas vezes relatam estar desestimulados para a disciplina porque entendem que não se relaciona diretamente à sua prática profissional (o que evidencia, mais uma vez, a dicotomia entre teoria e prática...). Ou, ainda, as disciplinas de metodologia da pesquisa são oferecidas à beira do encerramento do curso e se tornam, de certa forma, o atestado de que o percurso da graduação está acabando - e nada poderia ser mais emblemático para a materialização desse processo do que o TCC - o temido Trabalho de Conclusão de Curso, o que eleva ainda mais a necessidade de trazermos à tona os aspectos subjetivos inerentes à prática de pesquisa.

Nesses termos, dimensionar a instância metodológica de forma mais abrangente, como as conexões - epistemológicas, subjetivas - que vão sendo realizadas pelo sujeito pesquisador em seus processos de tomada de decisão, torna-se uma necessidade para a constituição do conhecimento. Mas, também, é um desafio, cujo enfrentamento encontra maior possibilidade de satisfação se realizado de forma coletiva.

Isso significa assumir a dimensão metodológica como um lugar formativo para os discentes e também para os professores, em que "vivenciada na práxis investigativa, a metodologia pode assim ser pensada e assumida como dimensão de formação do sujeito para a pesquisa, mas também para a vida” (BONIN, 2012, p. 44). Esse é um processo 
contínuo, no qual discentes e docentes estão inscritos e, por isso, assumem como um caminho nunca acabado.

Pensada a partir da subjetividade, dar espaço em sala de aula à importância da prática metodológica exige a configuração de um outro lugar pedagógico, afinal, "Os professores que esperam que os alunos partilhem narrativas confessionais mas não estão eles mesmos dispostos a partilhar as suas exercem o poder de maneira potencialmente coercitiva” (HOOKS, 2013, p. 19). A partir disso, talvez possamos encontrar na instância metodológica uma aliada no necessário contato com a alteridade, não o contrário, em que a discussão metodológica é sentida - não raras vezes - como justamente aquilo que está atrapalhando a realização de uma pesquisa.

\section{Referências}

BARICHELLO, E. M. R. A autoria na elaboração de uma tese. In: MOURA, C. P. D.; LOPES, M. I. V. D. Pesquisa em comunicação: metodologias e práticas acadêmicas. Porto Alegre: EDIPUCRS, 2016.

BARTH, D. L. Por uma compreensão conceitual de metodologia: textos científicos em encontros referenciais na Comunicação. 2018. 200 f., il. Tese (Doutorado em Comunicação) - Universidade de Brasília, Brasília, 2018.

BONIN, J. Revisitando os bastidores da pesquisa: práticas metodológicas na construção de um projeto de investigação. In: MALDONADO, A. E. Metodologias de pesquisa em comunicação: olhares, trilhas e processos. Porto Alegre: Sulina, 2011.

BONIN, J. A dimensão metodológica na orientação de pesquisas na Comunicação. In: MALDONADO, A. E.; MÁXIMO, M. E.; LACERDA, J.; BIANCHI, G. Epistemologia, investigação e formação científica em comunicação. Rio do Sul: UNIDAVI, 2012.

BONIN, J. A pesquisa exploratória na construção de investigações comunicacionais com foco na recepção. In: BONIN, J.; ROSÁRIO, N. Processualidades metodológicas: configurações transformadoras em Comunicação. Florianópolis: Insular, 2013.

BORSANI, M. A. Reconstrucciones metodológicas y/o metodologías a posteriori. Astrolabio, n. 13, 2014.

BRAGA, J. L. Para começar um projeto de pesquisa. Comunicação \& Educação, v. 10, n. 3, p. 288296, 2005.

BRAGA, J. L. Aprender metodologia ensinando pesquisa: incidências mútuas entre metodologia pedagógica e metodologia científica. In: MOURA, C. P. D.; LOPES, M. I. V. D. Pesquisa em comunicação: metodologias e práticas acadêmicas. Porto Alegre: EDIPUCRS, 2016.

FERRARA, L. D. Comunicação e epistemologia: retrato em branco e preto. Questões Transversais, v. 6, n. 12, 2019.

FREIRE, P. Pedagogia da autonomia: saberes necessários à prática educativa. São Paulo: Paz \& Terra, 2018.

GUEDES, H. T. V.; GUEDES, J. C. Student evaluation of the activity- "Research Project for Course Completion" as final stage of the scientific research axis in a medical school. Revista Brasileira de Educação Médica, v. 36, n. 2, p. 162-171, 2012.

HOOKS, B. Ensinando a transgredir: a educação como prática da liberdade. São Paulo: Editora WMF Martins Fontes, 2013. 
JACKS, N. A.; MENEZES, D.; PIEDRAS, E. Meios e audiências: a emergência dos estudos de recepção no Brasil. Porto Alegre: Editora Sulina, 2008.

JACKS, N. (Org.). Meios e audiências II: a consolidação dos estudos de recepção no Brasil. Porto Alegre: Sulina, 2014.

JACKS, N. et. al. (Org.). Meios e Audiências III: Reconfigurações dos estudos de recepção e consumo midiático no Brasil. Porto Alegre: Sulina, 2017.

LACERDA, J.; MAZIVIERO, L.; SILVA, A. A pesquisa da pesquisa em projetos de IC e TCC para a formação de novos pesquisadores. In: MALDONADO, E.; LACERDA, J.; BIANCHI, G. Epistemologia, investigação e formação científica em Comunicação. Natal: Editora da UFRN, 2012.

LOPES, M. I. V. Pesquisa em comunicação. São Paulo: Edições Loyola, 1990.

LOPES, M. I. V. Sobre o estatuto disciplinar do campo da Comunicação. In: LOPES, M. (Org.). Epistemologia da Comunicação. São Paulo: Edições Loyola, 2003.

LOPES, M. I. V. Reflexividade e relacionalismo como questões epistemológicas na pesquisa empírica de comunicação. In: BRAGA, J.L.; LOPES, M.I.V.; MARTINO, L.C. (Org.). Pesquisa Empírica em Comunicação. São Paulo: Paulus, 2010.

MACHADO, R. A Ciência no altar da devoração: antropofagia epistêmica e metodologia. In: MORALES, Y.; SOUSA, L.; LAPA, B. (Orgs.). Experiências metodológicas em pesquisas da comunicação. São Luís: EDUFMA, 2018.

MALDONADO, A. E. Teorias da comunicação na América Latina. São Leopoldo: UNISINOS, 2001.

MALDONADO, A. E. Teorias da comunicação na América Latina: enfoques, encontros e apropriações da obra de Verón. São Leopoldo: UNISINOS, 2003.

MALDONADO, A. E. A transmetodologia no contexto latino-americano. In: MALDONADO, A. E.; MÁXIMO, M. E.; LACERDA, J.; BIANCHI, G. Epistemologia, investigação e formação científica em comunicação. Rio do Sul: UNIDAVI, 2012.

MARTINO, L. M. S. Da teoria à metodologia: um ensaio sobre a elaboração de projetos de pesquisa em Comunicação. Revista Comunicação Midiática, v. 11, n. 2, p. 22-35, 2016.

MARTINO, L. M. S.; GROHMANN, R. Ensinar metodologia: questões epistemológicas nas proposições de 33 programas de ensino da disciplina em cursos de jornalismo. Comunicação \& Educação, v. 22, n. 2, p. 21-35, 2017.

MARTINO, L. M. S.; MARQUES, A. C. S. A afetividade do conhecimento na epistemologia. MATRIZes, v. 12, n. 2, 2018.

MARTINO, L. M. S.; MARQUES, A. C. S. Agradecimentos em Teses e Dissertações de Comunicação: as redes da subjetividade na produção acadêmica. Comunicação \& Inovação, v. 20, n. 43, 2019.

MILLS, C. W. Sobre o artesanato intelectual e outros ensaios. Rio de Janeiro: Zahar, 2009.

MOURA, C. Metodologia da pesquisa em Comunicação: estudo bibliográfico em disciplinas de Pós-Graduação. In: MOURA, C.; LOPES, M. I. V. Pesquisa em comunicação: metodologias e práticas acadêmicas. Porto Alegre: EDIPUCRS, 2016.

MOURA, C.; LOPES, M. I. V. Pesquisa em comunicação: metodologias e práticas acadêmicas. Porto Alegre: EDIPUCRS, 2016.

NAVARRO, R. F. Pesquisa e metapesquisa sobre comunicação na América Latina. MATRIZes, v. 13, n. 1, p. 27-48, 2019. 
OROZCO GÓMEZ, G. La investigación en comunicación desde la perspectiva cualitativa. La Plata: Ediciones de Periodismo y Comunicación, 2000.

PEROHOUSKEI, N. A.; ANGEL, B. L. D.; DE ANGEL, B. L. D. Experiência de assistência à docência na disciplina "trabalho de conclusão de curso" (TCC): desafios e perspectivas. GEOSABERES: Revista de Estudos Geoeducacionais, v. 2, n. 3, p. 59-65, 2011.

ROSÁRIO, N.; AGUIAR, L. Multiplicidades: perspectivas metodológicas para pensar a pesquisa científica em Comunicação. In: BONIN, J.; ROSÁRIO, N. Processualidades metodológicas: configurações transformadoras em Comunicação. Florianópolis: Insular, 2013.

SANTOS, C. K. et al. Pesquisa Científica no curso de Ciências Contábeis: Limites e contribuições ao aluno na elaboração do Trabalho de Conclusão de Curso. Revista Evidenciação Contábil \& Finanças, v. 5, n. 3, p. 140-156, 2017.

SEIBT, T.; BASEI, A. C., BONIN, J.; ROSÁRIO, N. Metodologia no TCC: antes, durante e depois. In: BONIN, J.; ROSÁRIO, N. Processualidades metodológicas: configurações transformadoras em Comunicação. Florianópolis: Insular, 2013.

SODRÉ, M. Ciência e método em Comunicação. In: LOPES, M. (Org.). Epistemologia da Comunicação. São Paulo: Edições Loyola, 2003.

\section{Laura Wottrich}

Professora do Departamento de Comunicação e Informação da Fabico/UFRGS. Graduada em Comunicação Social - Publicidade e Propaganda pela Universidade Federal de Santa Maria (2009), realizou o Mestrado em Comunicação na Universidade Federal de Santa Maria (2011) e Doutorado em Comunicação na UFRGS (2017). Integra o grupo de pesquisa Mídia e Práticas Culturais (UFRGS) e Processocom (Unisinos). Tem interesse em teorias da publicidade, estudos culturais e metodologia da pesquisa em comunicação. Autora do livro "Publicidade em Xeque: práticas de contestação dos anúncios” (Ed. Sulina, 2019). E-mail: laura.wottrich@ufrgs.br.

Recebido em: 02.06.2020

Aprovado em: 28.11.2020

Este artigo é publicado em acesso aberto (Open Access) sob a licença Creative Commons Attribution Non-Commercial (CC-BY-NC), que permite uso, distribuição e reprodução em qualquer meio, sem restrições, desde que sem fins comerciais e que o trabalho original seja corretamente citado.

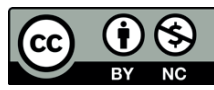

